\title{
Microstructure-twinning relations in beta-Ti alloys
}

\author{
$\underline{\text { Ivan Gutierrez-Urrutia }}^{1, \mathrm{a}^{*}}, \mathrm{Xin}_{\mathrm{Ji}}{ }^{1, \mathrm{~b}}$, Satoshi Emura ${ }^{1, \mathrm{c}}$ and Koichi Tsuchiya ${ }^{1,2, \mathrm{~d}}$ \\ ${ }^{1}$ National Institute for Materials Science, Sengen 1-2-1, Tsukuba, Ibaraki, 305-0047, Japan \\ ${ }^{2}$ Graduate School of Pure and Applied Sciences, University of Tsukuba, Ibaraki 305-0047, Japan \\ ${ }^{a}$ gutierrezurrutia.ivan@nims.go.jp, bji.xin@nims.go.jp, eemura.satoshi@nims.go.jp, ctsuchiya.koichi@nims.go.jp
}

\begin{abstract}
We have investigated twinning-microstructure relations in $\beta$-Ti alloys by statistical analysis of the evolving twin structure upon deformation by in-situ SEM testing and electron backscattering diffraction (EBSD). In particular, we have analyzed the effects of crystallographic orientation, grain size and chemical gradient structure on the nucleation and propagation behavior of $\{332\}<113>$ twins in a $\beta$-Ti-15 Mo (wt.\%) alloy and a multilayered $\beta$-Ti$10 \mathrm{Mo}-\mathrm{xFe}$ (x: 1-3 wt.\%). Microstructural parameters such as number of twins per grain and number of twins per grain boundary area were statistically analyzed.
\end{abstract}

\section{Introduction}

Deformation twinning is considered as a key deformation mode to design structural $\beta(\mathrm{bcc})$ Ti-alloys with enhanced mechanical properties. The formation of a twinning substructure upon straining tends to enhance the strain hardening behavior of polycrystalline materials and accordingly, novel alloy design strategies are currently developing to optimize the twinning substructure in bcc-Ti alloys [1-6]. In particular, in these alloys two twinning systems have been reported, namely, $\{112\}<111>$ and $\{332\}<113>[1-3,6-12]$. The nucleation mechanisms of these deformation twin systems are still under debate as well as the alloying dependence of the activation of these deformation modes. $\{332\}$ $<113>$ is the common twinning mode reported in bcc-Ti alloys $[1,2,4,5,7,8,11]$. This unusual twinning system has been ascribed to either the low magnitude of the shear modulus along $<110>$ directions on $\{110\}$ planes $\left(\mathrm{G}_{110}=((\mathrm{c} 11\right.$ c12)/2)) of the $\beta$ phase (this effect favors the specific atomic shuffling involved in the $\{332\}<113>$ twinning system [7]), or the $\alpha^{\prime \prime}-\beta$ phase transformation [8]. On the other hand, \{112\}<111> twinning system is the common twinning system in bcc metals [11]. However, in bcc-Ti alloys this twinning system has been only reported in a Ti-12 Mo alloy [6] and in some multicomponent alloy systems such as Ti-V-Fe-Al [3], Ti-Mo-Cr [12] and Ti-Mo-Cr-Al-Sn-Zr [5]. In polycrystalline materials, twinning behavior upon straining is strongly dependent on several microstructural features such as grain orientation, grain size, grain boundaries, pile-ups, crystal defects, slip bands, twin interfaces and cracks $[11,13-20]$. Deformation twins have been observed mostly to occur in grains whose orientation results in a high resolved shear stress on the twin system $[11,15]$. In particular, several works on $\beta$-Ti alloys have reported that $\{332\}$ $<113>$ twinning system follow Schmid's law with respect to the macroscopic applied stress [9, 21, 22]. However, recent reports on hep metals $(\mathrm{Mg}, \mathrm{Zr}$ and $\alpha$-Ti) have revealed that a large number of grains $(\sim 40-60 \%)$ with low macroscopic Schmid factors also contain deformation twins, which makes the validity of the Schmid's law questionable [23-26]. Grain boundaries and, in particular, their crystallographic structure and connectivity paly a strong role on twin nucleation and propagation. Grain boundaries (including triple lines and quadruple points) are the primary locations for stress concentrations in polycrystals that can supply the energy necessary to overcome activation barriers for twin nucleation to occur. For instance, grain boundary misorientation has been reported to play significant role on twin nucleation and propagation in hep metals $[23,24,26]$. These results underline the importance of microstructure on twinning behavior in bcc-Ti alloys. The present work reports quantitative analysis of microstructure-twinning relations in $\beta$-Ti alloys. These relations were investigated by statistical analysis of the evolving twin structure upon deformation at room temperature by in-situ SEM testing and electron backscattering diffraction (EBSD).

\section{Experimental section}

Two bcc-Ti alloys were investigated, namely, a Ti-15Mo (wt.\%) alloy and a multilayered Ti-10Mo-xFe (x: 1-3; wt.\%) alloy. The Ti-15Mo (wt.\%) alloy was prepared by cold crucible levitation melting under Ar gas atmosphere. The ingot was hot forged at $1000^{\circ} \mathrm{C}$ to $40 \%$ thickness reduction and thereafter hot rolled at $900^{\circ} \mathrm{C}$ to $75 \%$ thickness reduction followed by air-cooling. The hot-rolled material was subsequently solution-treated for $1 \mathrm{~h}$ at $900^{\circ} \mathrm{C}$ followed by water quenching. The as-hot rolled material was finally annealed for $1 \mathrm{~h}$ at $1000^{\circ} \mathrm{C}$. The multilayered alloy consisted of ten alternative layers of Ti-10Mo-1Fe and Ti-10Mo-3Fe alloys and it was processed following the method described in [27]. Tensile samples were machined out from the Ti alloys along the rolling direction (RD). The tensile samples of the multilayered alloy had $18 \mathrm{~mm}$ gage length, $4 \mathrm{~mm}$ gage width and $2.5 \mathrm{~mm}$ gage thickness. Tensile tests were performed

(C) The Authors, published by EDP Sciences. This is an open access article distributed under the terms of the Creative Commons Attribution License 4.0 (http://creativecommons.org/licenses/by/4.0/). 
in an Instron 5581 tensile machine at room temperature and at an initial strain rate of $1 \times 10^{-5} \mathrm{~s}^{-1}$. In-situ SEM tensile tests were conducted in a tensile stage manufactured by TSL Solutions Japan (Sagamihara-shi, Japan) using a $1000 \mathrm{~N}$ load cell. In-situ SEM tensile samples were flat dog-bone shaped samples with gage dimensions of $2.0 \mathrm{~mm}$ wide, 1.0 $\mathrm{mm}$ thick and $10 \mathrm{~mm}$ long. Mechanical tests were performed at room temperature at a constant displacement rate of $0.005 \mathrm{~mm} / \mathrm{s}$, which is equivalent to a strain rate of $2 \times 10^{-4} \mathrm{~s}^{-1}$, to $\epsilon \sim 10 \%$ by using a screw-driven tensile stage placed inside the SEM. SEM images were taken in a Sigma Zeiss field emission gun scanning electron microscope (FEGSEM) equipped with a TSL orientation imaging microscopy (OIM) EBSD system. EBSD maps were performed at 20 $\mathrm{kV}$, at working distance of $15 \mathrm{~mm}$ and step sizes between $100 \mathrm{~nm}$ and $2 \mu \mathrm{m}$. Statistical analysis of surface twinning events was evaluated over 350 twinning events. We only evaluated twins that significantly contribute to the overall plastic deformation, i.e. micron-scale twins that are associated with a nucleation event followed by in-grain propagation of a detectable twin. Active twin systems were identified by the twin place trace approach described in [28]. Schmid factors of active twin variants were calculated with respect to the sense and direction of the macroscopic loading, using the twin plane $\left(\mathrm{K}_{1}\right)$ and shear direction $\left(\eta_{1}\right)$. For each grain, the twelve possible twin variants v(i) were classified in order of decreasing Schmid factor $\mathrm{m}(\mathrm{i})$ (i: 1, .. 12). Variant $\mathrm{v}(1)$ has the highest Schmid factor $\mathrm{m}(1)$ and the twelfth variant $\mathrm{v}(12)$ the lowest $\mathrm{m}(12)$.

\section{Results and discussion}

\subsection{Effect of crystallographic grain orientation}

We have investigated the effect of crystallographic grain orientation on $\{332\}<113>$ twinning in a bcc-Ti-15 Mo alloy. Fig. 1 shows the twin structure of the Ti-15Mo alloy tensile deformed to $\sigma: 430 \mathrm{MPa} / \mathrm{e}: 0.9 \%$ (a) and $\sigma: 530 \mathrm{MPa} / \epsilon$ : $8.8 \%$ (b). It can be seen that winning is activated readily after yielding. EBSD reveals that the twin structure consists of primary twins, i.e. twin variants with the highest Schmid factor v(1), and secondary twins (twin variants with Schmid factors $\mathrm{v}(2)$ to $\mathrm{v}(12)$ ). Primary twins nucleate at grain boundaries (including triple lines and quadruple points) and secondary twins nucleate at both grain boundaries and primary twin interfaces.
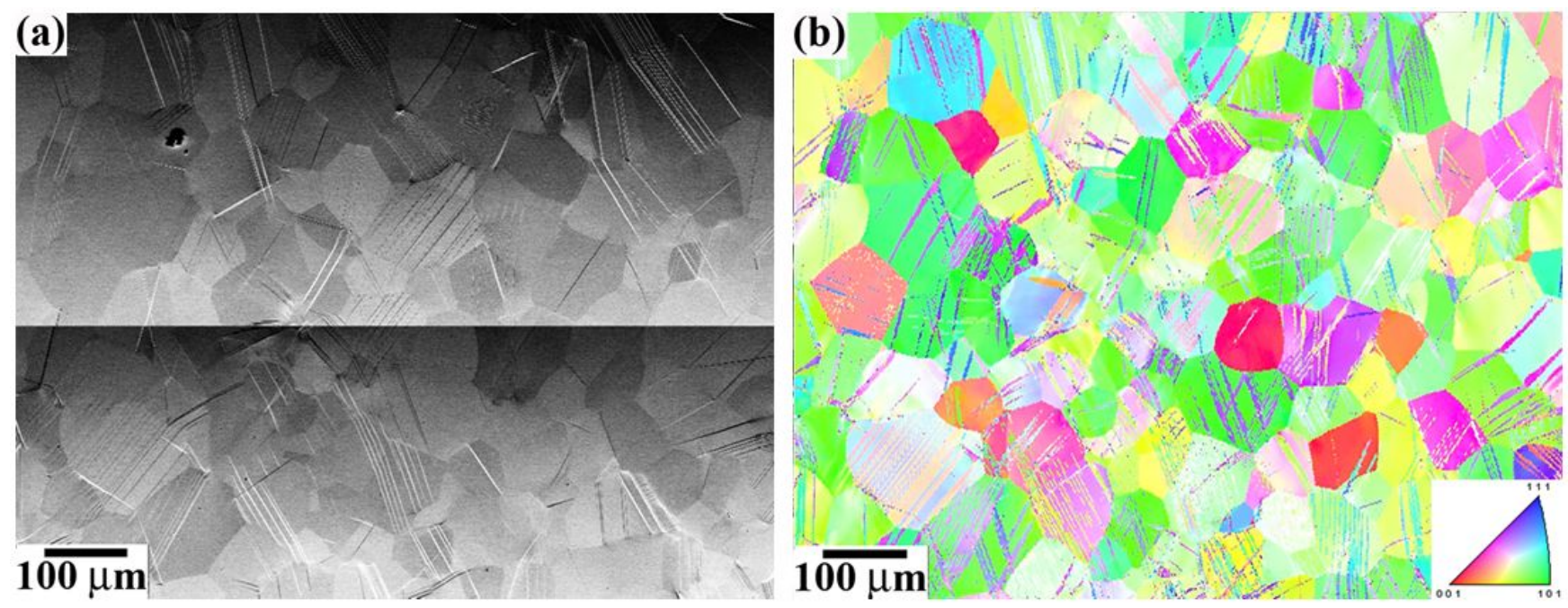

Fig. 1. (a) SE-SEM image of the $\{332\}<113>$ twin structure strained to $430 \mathrm{MPa} / \epsilon$ : $0.9 \%$ in a Ti-15Mo alloy; (b) EBSD map along TD (deformation stage: $530 \mathrm{MPa} / \epsilon: 8.8 \%$ ) [28].

The effect of crystallographic grain orientation on deformation twinning is analyzed in Fig. 2. In particular, Fig. 2(a) shows the distribution of the Schmid factor for twinning $m$ of the active twin variants. This plot reveals that most of the active twin variants follow the Schmid law with respect to the macroscopic applied stress, i.e. $80 \%$ of the twinned grains are favorably oriented for twinning with $\mathrm{m}>0.4$. This finding agrees with several reports on $\{332\}<113>$ twinning in several $\beta$-Ti alloys $[9,21,22]$. Interestingly, this plot also shows that twins appeared in grains over a wide range of $\mathrm{m}$, i.e. they also appeared in grains oriented less favorably for twinning. The relative frequency of the twin variants is plotted in Fig. 2(b). This plot shows that most of the active twin variants ( 85\%) are v(1)-type, i.e. they correspond to the highly stressed twin system. These findings show that about $15-20 \%$ of the twinning events analyzed in the present bcc-Ti alloy deviate from the Schmid law. Similar observations to those reported here have been recently observed on $\{10-12\}$ twinning in hep metals such as $\operatorname{Mg}$ and $\operatorname{Zr}[14,24,25,29]$. However, the fraction of twinned grains with unfavorable orientations observed in these materials, i.e. $\sim 40-60 \%$, is much higher than that observed in the present study $(\sim 20 \%)$. This effect is related to the underlying mechanism controlling the growth of twin variants with low macroscopic Schmid factor that can be ascribed to phenomena such as local strain accomodation effects, competition between twin back-stress and in-grain stress state, and stress fluctuations at grain boundaries [25, 
30, 31]. Interestingly, our analysis reveals that most of the growth twins correspond to the higher stressed variant. This result agrees with that obtained by Hanada et al. [32] in single crystals of $\beta$-TiNb alloys.
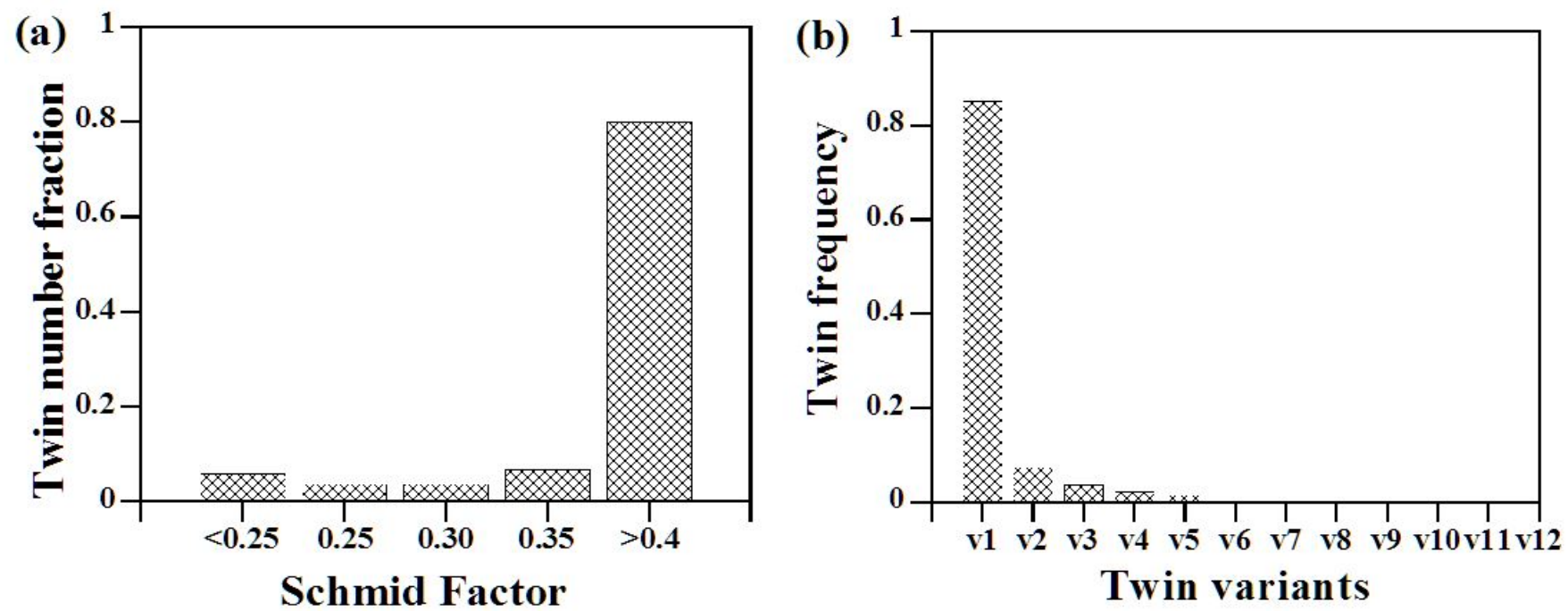

Fig. 2. (a) Twin number fraction as a function of the Schmid factor for twinning; (b) Twin frequency of v(1)...v(12)-type active twin variants [28].

\subsection{Effect of grain size}

The role of grain size on $\{332\}<113>$ twinning was analyzed in the Ti-15 Mo alloy system by the analysis of the evolution of primary twinning upon straining. Two samples were analyzed, namely, a fine grain size sample (SG, average grain size of $40 \mu_{\mathrm{m}}$ ) and a coarse grain sample (LG, average grain size of $120 \mu \mathrm{m}$ ). Fig. 3 shows the number of twins per grain ntw as a function of the plastic strain (a) and macroscopic stress (b). These plots show that the evolution of $n_{t w}$ with plastic strain follows the same trend on both samples. Specifically, ntw gradually increases with plastic strain up to strain level of $\varepsilon \sim 1.5-2.5 \%$. Thereafter, it rises in a moderate fashion. This plot also reveals that the grain size has significant role on $\mathrm{ntw}$. Specifically, $\mathrm{ntw}$ in LG is about 1.5 times higher than that in SG. The evolution of ntw with stress exhibits a more complex trend (Fig. 3(b)), which is related to the flow stress dependence on twin parameters such as twin thickness and twin spacing. It can be seen that in the SG sample ntw scales almost linearly with stress within the whole deformation range, up to $\sigma \sim 540 \mathrm{MPa}$. On the other hand, in the LG sample ntw scales linearly with stress only within the early stages of deformation, up to $\sigma \sim 450 \mathrm{MPa}$. From that point on, ntw increases remarkably from 4.0 to 9.8 in a small stress range of about $75 \mathrm{MPa}$. The scaling of ntw with grain size has been recently explained by a probabilistic twin nucleation model where twin nucleation is described as a dissociation process of grain boundary defects into twinning partials to create a twin nucleus [26,31]. The number of successful conversion events is considered to follow a stochastic process where the rate is assumed to increase with local stress.
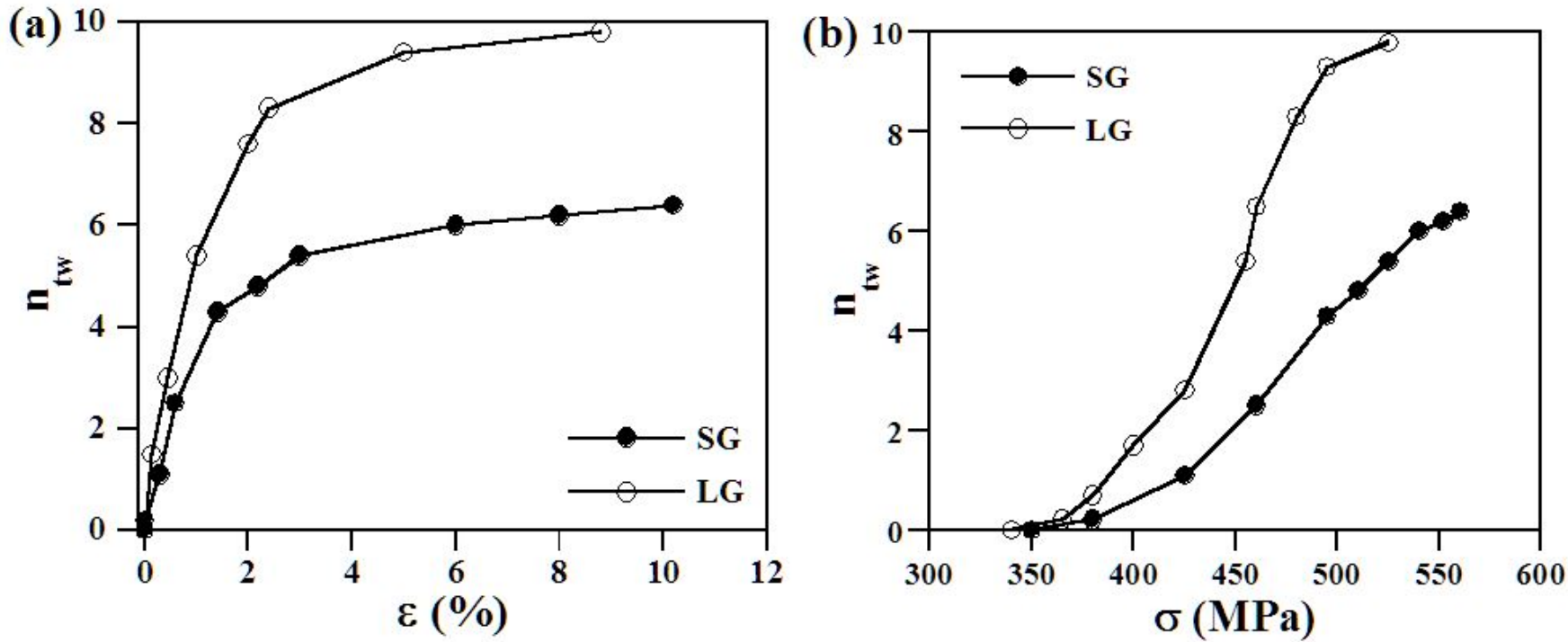

Fig. 3. Evolution of the number of twins ntw with plastic strain, $\epsilon$, (a) and macroscopic stress, $\sigma$, (b). SG: Fine-grained sample; LG: Coarsegrained sample [28]. 
We have also analyzed the effect of grain size on the number of twins per unit of grain boundary area, $\mathrm{n}^{\mathrm{GB}_{\mathrm{t}}}$. Details of the analysis are described in [28]. The evolution of $\mathrm{n}^{\mathrm{GB}_{\mathrm{t}}}$ with strain level for both samples is plotted in Fig. 4. This figure reveals that $\mathrm{n}^{\mathrm{GB}_{t}}$ is significantly reduced with grain size (about six times). It can be also seen that both samples exhibit similar evolution of $\mathrm{n}^{\mathrm{GB}_{\mathrm{t}}}$ with strain, namely, a rapid increase of $\mathrm{n}^{\mathrm{GB}_{\mathrm{t}}}$ with plastic strain up to strain level of $\varepsilon \sim$ $2.5-3.0 \%$, and thereafter the increase is slightly moderated. The scaling of $\mathrm{n}^{\mathrm{GB}_{\mathrm{t}}}$ with grain size can be attributed to the low resolved stress acting on the twin systems of the coarse-grain sample [28].

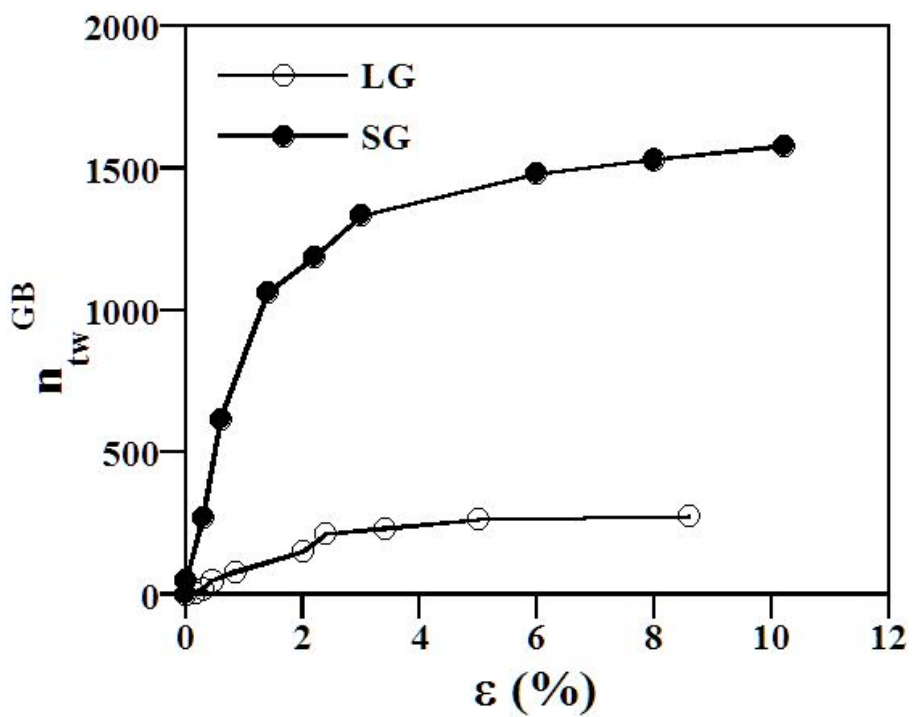

Fig. 4. Evolution of the number of twins per grain boundary area $\mathrm{n}^{\mathrm{GB}_{\mathrm{t}}}$ with plastic strain, $\epsilon$. SG: Fine-grained sample; LG: Coarse-grained sample [28].

\subsection{Effect of chemical gradient}

Homophase interfaces such as grain boundaries, annealing twins, and mechanical twins play a significant role on the propagation of mechanical twins in bcc metals. In particular, grain boundaries and twin interfaces can act as strong barriers on twin propagation and, depending on the crystallographic orientation of the crystals involved, may even completely hinder twin propagation. We have analyzed the effect of a chemical graded structure on the propagation of $\{332\}<113>$ deformation twins in a Ti-10Mo-xFe $(\mathrm{x}=1-3)$ alloy. The alloy contains a macroscopic gradient of $\mathrm{Fe}$ ranged between 1 and $3 \mathrm{wt} \% \mathrm{Fe}$ that is distributed in the form of bands parallel to $\mathrm{RD}$, while Ti and Mo are homogeneously distributed within the Fe-graded structure, Fig. 5. These bands are about $130 \mu \mathrm{m}$ thick and are stacked between the original Ti-10Mo-1Fe and Ti-10Mo-3Fe layers, which are about $50 \mu \mathrm{m}$ thick. The width of the Fe-graded structure is determined by the specific thermomechanical conditions [27].

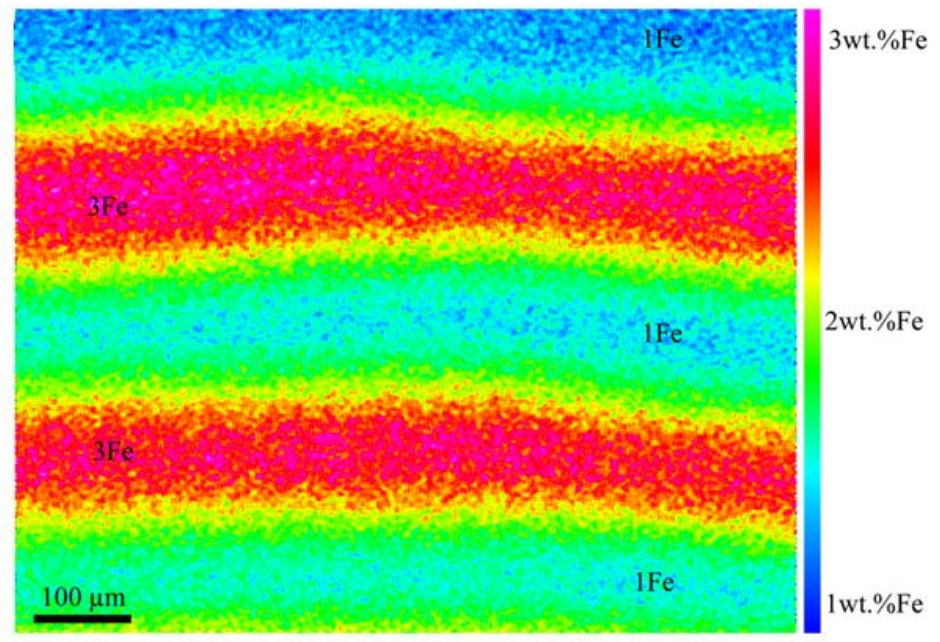

Fig. 5 Typical EPMA map of Fe distribution within a grain of the Ti-10Mo-xFe $(x=1-3)$ alloy.

We observe that the Fe-graded structure has a significant influence on the twin propagation behavior of $\{332\}<113>$ twins. In particular, deformation twins are interrupted in the grain interiors at a specific Fe content, namely, about 2 
wt\% Fe, Fig. 6. EPMA and high-resolution EBSD mapping do not reveal the formation of any intragranular homophase interface such as diffuse chemical interface, low angle grain boundary or annealing twin. Under the current thermomechanical conditions, the role of precipitates such as $\omega$-omega phase on the precipitate-twin interaction can be ruled out due to the small volume fraction $(<0.01)$ and their shearable nature $[33,34]$. These findings indicate that $\mathrm{Fe}$ content in solid solution is the main microstructural parameter controlling twin propagation in the chemical graded TiMo-Fe alloy.
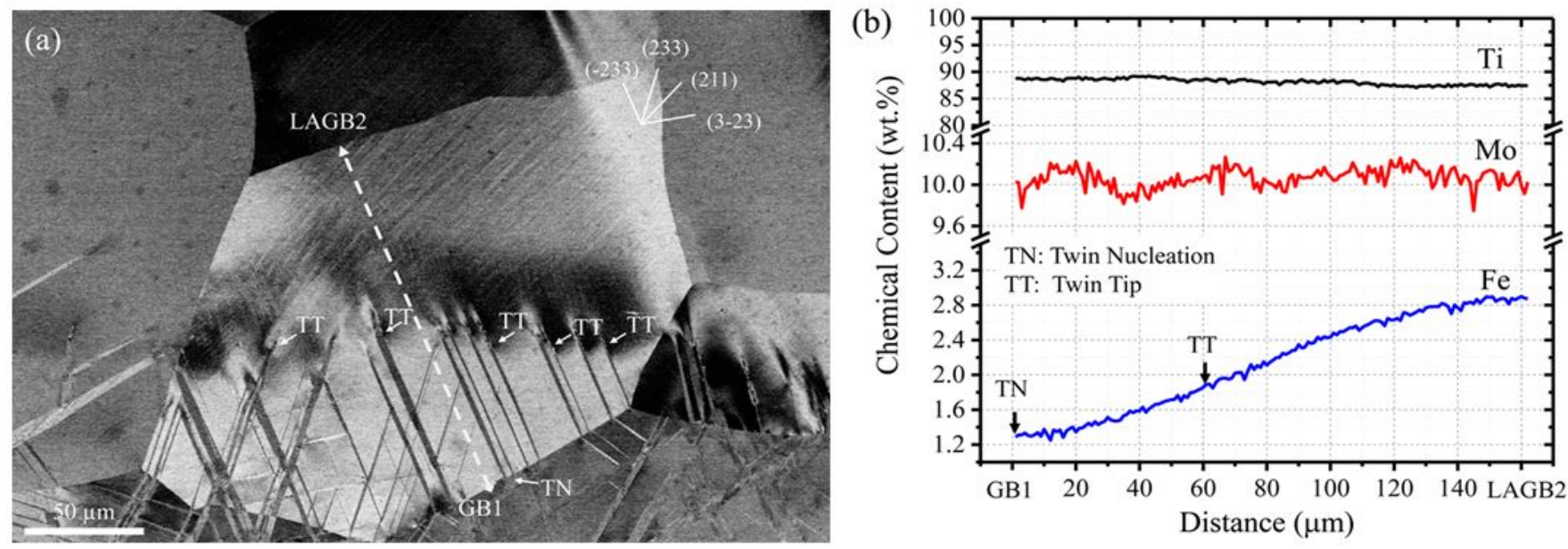

Fig. 6. (a) ECCI image of the twin structure of the Ti-10Mo-xFe $(x=1-3)$ alloy strained to $\epsilon \sim 4 \%$; (b) Chemical line analysis performed by EPMA along the dashed line of the grain shown in (a). TN: twin nucleation; TT: twin tip; GB: grain boundary; LAGB: low angle grain boundary [27].

In particular, we found that $\mathrm{Fe}$ content has strong influence on the twinning stress in the present alloy system [28]. Our results reveal that the stress to propagate a twin plate that is nucleated in the Fe-lean region $(\sim 1 \mathrm{wt} \% \mathrm{Fe})$ and propagates through the Fe-graded structure increases significantly with the twin propagation length from the grain boundary. At the current deformation conditions, the macroscopic applied stress is about $830 \mathrm{MPa}$, which is slightly higher than the twinning stress for the Ti-10Mo-2Fe alloy $\left(\sigma_{\mathrm{tw}}=780 \mathrm{MPa}\right)$. This result indicates that twins nucleated in the Fe-lean region $(\sim 1 \mathrm{wt} \% \mathrm{Fe})$ are able to propagate within the interior of a grain up to an area containing about 2 $\mathrm{wt} \% \mathrm{Fe}$, which is close to the experimental value of $1.8 \mathrm{wt} \% \mathrm{Fe}$.

\section{Conclusions}

We have investigated microstructure-twinning relations in the $\{332\}<113>$ twin system by quantitative characterization of the deformation twin structure in a polycrystalline $\beta$-Ti-15Mo (wt.\%) alloy and a multilayered $\beta$-Ti-10Mo-xFe (x: 1 3 wt.\%) alloy by in situ SEM and EBSD. We find that most of the primary twins $(\sim 80 \%)$ follow the Schmid's law with respect to the macroscopic stress. We also observe that most of the growth twins $(\sim 85 \%)$ correspond to the higher stressed variant. These findings suggest that the twin systems with the highest Schmid factor are also those systems that are most strongly stressed at the grain level. We find that in the grain size range studied here $\left(40-120 \mu_{\mathrm{m}}\right.$ ), grain size has strong influence on the number of twins per grain $n_{t w}$ and number of twins per grain boundary area $n^{\mathrm{GB}_{t}}$. We ascribe these effects to the grain size dependence of different twin stress components. On the other hand, we observe that a Fe-graded structure has strong influence on the twin propagation behavior so that twins are interrupted at the grain interiors. We ascribe this effect to the role of Fe content on twinning stress.

\section{Acknowledgments}

The authors wish to acknowledge financial support from NIMS.

\section{References}

[1] M. Marteleur, F. Sun, T. Gloriant, P. Vermaut, P.J. Jacques, F. Prima, Scripta Mater. 66 (2012) 749-752.

[2] F. Sun, J.Y. Zhang, M. Marteleur, C. Brozek, E.F. Rauch, M. Veron, P. Vermaut, P.J. Jacques, F. Prima, Scripta Mater. 94 (2015) 17-20. 
[3] M. Ahmed, D. Wexler, G. Casillas, O.M. Ivasishin, E.V. Pereloma, Acta Mater. 84 (2015) 124-135.

[4] C. Brozek, F. Sun, P. Vermaut, Y. Millet, A. Lenain, D. Embury, P.J. Jaques, F. Prima, Scripta Mater. 114 (2016) 6064.

[5] L. Ren, W. Xiao, C. Ma, R. Zheng, L. Zhou, Scripta Mater. 156 (2018) 47-50.

[6] F. Sun, J.Y. Zhang, M. Marteleur, T. Gloriant, P. Vermaut, D. Laillé, P. Castany, C. Curfs, P.J. Jacques, F. Prima, Acta Mater. 61 (2013) 6406-6417.

[7] H. Tobe, H.Y. Kim, T. Inamura, H. Hosoda, S. Miyazaki, Acta Mater. 64 (2014) 345-355.

[8] M.J. Lai, C.C. Tasan, D. Raabe, Acta Mater. 111 (2016) 173-186.

[9] E. Bertrand, P. Castany, I. Peron and T. Gloriant, Scripta Mater. 64 (2011) 1110-1113.

[10] I. Gutierrez-Urrutia, C.-L. Li, K. Tsuchiya, J. Mater. Sci. 52 (2017) 7858-7867.

[11] J.W. Christian, S. Mahajan, Prog. Mater. Sci. 39 (1995) 1-157.

[12] J. Gao, Y. Huang, D. Guan, A.J. Knowles, L. Ma, D. Dye, W.M. Rainforth, Acta Mater. 152 (2018) 301-314.

[13] R. Priestner, W.C. Leslie, Phil. Mag. 11 (1965) 895-916.

[14] M.R. Barnett, Z. Keshavarz, A.G. Beer, X. Ma, Acta Mater. 56 (2008) 5-15.

[15] M.A. Meyers, O. Vöhringer, V.A. Lubarda, Acta Mater. 49 (2001) 4025-4039.

[16] I. Gutierrez-Urrutia, D. Raabe, Scripta Mater. 66 (2012) 992-996.

[17] M.R. Barnett, Scripta Mater. 59 (2008) 696-698.

[18] W.Z. Han, Z.F. Zhang, S.D. Wu, S.X. Li, Phil. Mag. 88 (2008) 3011-3029.

[19] A. Ghaderi, M.R. Barnett, Acta Mater. 59 (2011) 7824-7839.

[20] Y.T. Zhu, X.Z. Liao, X.L. Wu, J. Narayan, J. Mater. Sci. 48 (2013) 4467-4475.

[21] W.L. Wang, X.L. Wang, W. Mei, J. Sun, Mater. Char. 120 (2016) 263-267.

[22] X. Min, S. Emura, X. Chen, X. Zhou, K. Tsuzaki, K. Tsuchiya, Mater. Sci. Eng. A 659 (2016) 1-11.

[23] L. Capolungo, P.E. Marshall, R.J. McCabe, I.J. Beyerlein, C.N. Tomé, Acta Mater. 57 (2009) 6047-6056.

[24] I.J. Beyerlein, L. Capolungo, P.E. Marshall, R.J. McCabe, C.N. Tomé, Phil. Mag. 90 (2010) 2161-2190.

[25] Z.-Z. Shi, Y. Zhang, F. Wagner, P.-A. Juan, S. Berbenni, L. Capolungo, J.-S. Lecomte, T. Richeton, Acta Mater. 83 (2015) $17-28$.

[26] S.R. Niezgoda, A.K. Kanjarla, I.J. Beyerlein, C.N. Tomé, Int. J. Plast. 56 (2014) 119-138.

[27] I. Gutierrez-Urrutia, C.-L. Li, S. Emura, X. Min, K. Tsuchiya, Sci. Tech. Adv. Mater. 17(1) (2016) 220-228.

[28] I. Gutierrez-Urrutia, C.-L. Li, X. Ji, S. Emura, K. Tsuchiya, Sci. Tech. Adv. Mater. 19(1) (2018) 474-483.

[29] L. Capolungo, I.J. Beyerlein, C.N. Tomé, Scripta Mater. 60 (2009) 32-35.

[30] J. Jonas, S. Mu, T. Al-Samman, G. Gottstein, L. Jiang, É. Martin, Acta Mater. 59 (2011) 2046-2056.

[31] I.J. Beyerlein, C.N. Tomé, Proc. R. Soc. A 466 (2010) 2517-2544.

[32] S. Hanada, A. Takemura, O. Izumi, Trans. Jpn. Inst. Met. 23(9) (1982) 507-517.

[33] Gysler A, Lutjering G, Gerold V, Acta Metall. 22 (1974) 901-909.

[34] Banerjee S, Naik UM, Acta Mater. 44 (1996) 3667-3677. 